\section{Effectiveness of PowerPaper presentation as an innovative instructional material in teaching science 5 in the selected public schools in Taytay, Rizal}

\author{
Anacaya, Raymond Z. $\$ \\ Emilio Aguinaldo College, Philippines (anacayaraymond@gmail.com)
}

Received: 30 March 2021

Available Online: 21 June 2021
Revised: 14 May 2021 DOI: $10.5861 /$ ijrse.2021.649

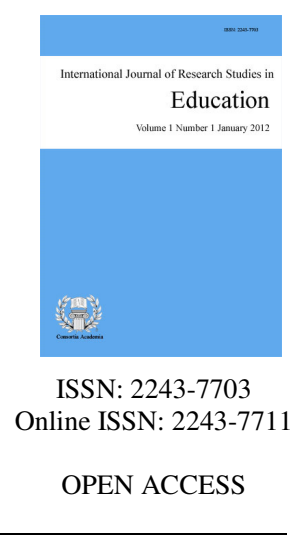

\title{
Abstract
}

PowerPoint Presentation (PPT) is a common instructional software or program used by teachers in ICT-rich classrooms. However, many public schools in the country still lack or have insufficient access to ICT resources. Therefore, this study sought to assess the effectiveness PowerPaper Presentation (PPP). PowerPaper Presentation is a teacher-designed low-cost and low-tech innovative alternative to PowerPoint Presentation in promoting student learning of selected topic in Science 5 using a quasi-experimental method that adopted the pre-test-post-test design. Three groups of student participants from selected public elementary schools totaling 136 participated in the study composed of 45 students constituting the control group from Corazon C. Aquino Elementary School, 46 students serving as experimental group A from Bagong Pag-Asa Elementary School Annex, and 45 students serving as experimental group B from San Juan Elementary School Annex from the Division of Rizal. The intervention was like teaching a selected topic in Science 5 using PowerPaper Presentation for the experimental groups and without PowerPaper Presentation for the control group. First, a pre-test was administered to the three groups before the teaching process. Then, the same test was issued as a post-test after the teaching process. Finally, the results were statistically analyzed. Analysis of the pre-test results using one-way analysis of variance revealed no significant differences in the pre-test scores of the control group and the two experimental groups. However, as regards the post-test results, analysis of variance revealed that the post-test scores of the two experimental groups are statistically comparable. In contrast, the post-test scores of the control group are significantly lower than the experimental groups. Furthermore, the normalized learning gains of the two experimental groups, while statistically comparable, are substantially higher than the learning gains of the control group. These results imply that PowerPaper Presentation significantly improved students' learning of the selected topic in Science 5

Keywords: PowerPaper presentation; improve; low-cost; innovative; intervention 


\section{Effectiveness of PowerPaper presentation as an innovative instructional material in teaching science 5 in the selected public schools in Taytay, Rizal}

\section{Introduction}

Manner of education is a complicated-forceful teaching-learning system that involves learners and teachers. Teachers play a vital role because they orchestrate and ultimately integrate varying elements of education to meet every learner's expected goal and objective. These lead to an observation that teachers should have ideally mastered how teaching and learning function.

As the person who processes education, a teacher must possess the character of being creative, dynamic, effective, and innovative. At some point, the fact remains that every classroom set-up and needs are different from one to another. Therefore, teachers must offer each classroom diverse types and degrees of stimuli to achieve the expected responses. Undeniably, challenges in the education system become immense and sometimes staggering, especially in information and communication technologies such as social networking websites and the internet that enormously change the design of education and how we teach the learners (Reid, 2002).

However, because of the difference in the monetary means, no longer everyone, every School, not every classroom, teacher, and student, has a get right of entry to a more advanced educational generation being developed (Rowsell, Morrell, \& Alvermann, 2017). Only those with monetary means, private schools in the Philippines, most likely can take advantage of ICT advancement in terms of education, which will result in better teaching that will lead to better learning. What should the public institution do to address these gaps? What should a public-school teacher do when caught in a scene where students can hardly be in touch with ICT? Commonly used ICT-based instruction is PowerPoint presentation (Star, 2011), based on some current studies. How can teachers maximize this application's benefits if teachers and students can barely access new technology? The answer lies in the teacher's ability to be innovative. Such a reality in the Philippine public-school setting encourages the teacher to provide the students with an equally low-cost and low-tech useful alternative teaching-learning material by unleashing his or her innovative and creative power.

One of the primary duties of teachers is to choose audio-visual teaching materials that will address the needs of different learners. They decide what teaching substances/materials are suitable for the concepts and appropriate to the needs of students, materials that can be individually made and use in their teaching method. Teachers have to construct and modify existing instructional materials by adding or removing features, especially when these apt materials are not accessible. They are always reminded not only to look for motivating visual materials but also to bring about effective and efficient content. (Mc Guire, 2018).

The current study focused on seeking an answer to the digital gap in the classroom by creating and innovating visual instructional material that the researcher called "PowerPaper Presentation." "PowerPaper Presentation" or PPP is an innovative educational material designed as an alternative to accommodate functions PowerPoint Presentation. The idea of constructing inexpensive teaching materials with equally effective and efficient outcomes. Despite the unavailability of more advanced technology in the classroom, the researcher's innovation of this instructional material was constructed to address this gap using the researcher's simple creativity and creative inspiration.

\subsection{Innovative instructional materials and technology}

In this Millennial Era, catching learners' attention is one of the many challenges teachers face because of many competing distractions. Thus, designing an educational device to awaken children's interest in their science 
lessons falls under strategies and methods to catch children's attention and focus on the task. Along this line, the "PowerPaper Presentation" has been used by the researcher in teaching his lesson with positive results. The PowerPaper Presentation is used to address the least mastered skills of every learner. Specifically, the use of PowerPaper Presentation aims to increase the proficiency level of every learner by presenting the science lessons in a novel way that will catch and hold their attention.

The PowerPaper Presentation or PPP is a multi-purpose instructional device that can be used in any topic in science. It is, however, especially appropriate in explaining Cycles, Processes, and Steps, such as the water cycle, food web, food chain, specific functions of the human body, parts of flowers, parts of seeds, and animal life cycle. It is a handy, portable, low-cost device that anyone can construct. Every learner can manipulate this innovative instructional material during their free time, be used efficiently, and promote students' interest due to its visual effects. Also, it can be replicated in small-scale models by teachers for the student's individual use to maximize their understanding of the lesson.

The device is made from any used cardboard or colored paper. It has "unending" flippable four slides and pop-up models so that children will have fun opening it while learning the science concepts. In recognition of the device's innovative features, it has won first place in a district-wide competition showcasing teachers' creativity in presenting their lessons.

Since not all schools have access to modern technology, the PowerPaper Presentation can be used as an alternative to PowerPoint Presentation. Hence it features the basic function of the PowerPoint Presentation, like the transitional effects of slides. Moreover, the PowerPaper Presentation can be used even without electricity and can be used as an alternative in power failures. In addition, this can be used by teachers who cannot use and make PowerPoint Presentations in delivering their lesson, especially those who were considered Baby Boomers and Gen $\mathrm{X}$ teachers.

\subsection{Information processing model}

As applied in the study, the Information Processing Model makes the PowerPaper Presentation (PPP) a stimulus to the students in flippable slides and pop-up models. The visual inputs (in the form of 3-7 units) are transferred and stored in the sensory memory, which lasts for a short duration (0.5-3 s). Hence, it is critical to hold students' attention without overloading it. Otherwise, the information (if uninteresting and overloading) will not be attended to and be easily forgotten. However, if properly attended to by the students because their attention has been caught and focused on the PPP, the information will be transferred to the working memory, capable of attending to 7-9 chunks for 5-15 without rehearsal. Otherwise, it will be forgotten.

If the information is encoded in the form the brain uses with proper rehearsal, it will be transferred to the long-term memory. Otherwise, the data is "lost." Information successfully stored in the long-term memory is considered "learned." Once needed, it can be easily retrieved back to the short-term memory, also through the working memory, for possible use with new information in the process of being "learned." Thus, as applied in the present study, the PPP is designed to be attractive and provide scientific information in "chewable" units. Further, the students can review the PPP in their small-scale model, thereby addressing rehearsal and encoding. Finally, students' understanding is facilitated as the information is effectively transferred into the long-term memory from which it can be retrieved when learning new relevant materials.

\subsection{Power of PowerPaper presentation as an innovative instructional material}

Traditionally, classroom settings are dominated by the use of the 'chalk and talk' approach. This teaching strategy allows the direct delivery of messages from the teachers to the learners during instruction. Furthermore, this teaching method is considered the widely used approach in teaching. However, this teaching strategy is not enough to meet the learning needs of $21^{\text {st }}$-century learners, who are characterized by diversity in the learning process. Because of this, teachers are encouraged to use other teaching approaches other than the 'chalk and talk' 
teaching method.

Over the past years, the advent of technology paved the way for designing certain materials, which teachers can use inside the classroom during the instruction processes. These materials, collectively called instructional materials, are currently being widely used among teachers for discussion matters. Instructional materials maximize the best possible outcomes of the learning process by stimulating the senses of the learners. Stimulation of these senses during instruction enhances the ability of the learners to learn more from the topic of interest. So it is because students with diverse learning needs are captured with the use of these instructional materials.

They continuously design these instructional materials due to their creativeness and resourcefulness. In addition, teachers want to provide the best possible instruction to the learners. These two characteristics that embodied a teacher allow these instructional materials to be innovative. In a sense, innovative instructional materials are improved instructional materials to meet learners' diverse learning needs, especially in the $21^{\text {st }}$ century. Because of their unparalleled importance in teaching, it is vital to note that innovative instructional materials should not be ignored since they aid teachers in the learning process. Furthermore, innovative instructional materials, in the future, should be further improved more since the learning needs of diverse students change as time progresses. Given this, innovative instructional materials should be investigated, especially in teaching science, in terms of their effects on the learners' performance.

Despite the proven advantages of PowerPoint Presentations, the digital divide confronting many countries and many schools result in the inaccessibility of PPT to many teachers and students. Therefore, teachers need to continue to rely on their creativity and resourcefulness to leverage the best features of more advanced technology and integrate them into low-cost instructional materials. Hence, the present study on PowerPaper Presentation is an innovation in instructional materials preparation that bridges the digital or ICT gap in schools that are not well blessed with access to ICT-based instructional media and equipment.

\section{Methodology}

The proposed study used the quasi-experimental pre-test-post-test design to obtain the necessary data and information to determine the effectiveness or efficacy of the PowerPaper Presentation in promoting pupils' understanding of selected science concepts to Grade 5 students in the selected schools. A simple experiment was carried out to test the effectiveness of the PowerPaper Presentation in promoting the pupils' mastery level of the selected topic. Three heterogeneous groups of similar learning abilities will be created: a control group of about 45-50 students and two experimental groups of about 45-50 students. The control group was taught without PowerPaper Presentation, while the experimental group was conducted using the PPP.

Grade 5 pupils of the selected three schools in the District of Taytay, Division of Rizal, were the target respondents of this study. One section from Grade 5 in Corazon C. Aquino Elementary school served as the control group. In comparison, 1 section from Grade 5 in Bagong Pag-Asa Elementary School Annex and 1 section in San Juan Elementary School Annex served as the experimental groups. The present experiment aimed to establish that the use of PowerPaper Presentation resulted in significantly better performance than the traditional method in selected topics in Science 5. Two groups of classes with comparable abilities were chosen, with one group serving as the experimental group while the other as the control group. The experiment was carried out for at least 1 class session.

\subsection{Experimental procedure}

A pre-test was administered at the beginning of the lesson. At the end of the experiment, the post-test was administered. The PowerPaper Presentation served as the experimental intervention. The control group did not use the PPP, while the experimental group used the PPP extensively throughout the class session. The pre-and 
post-test scores of each group were compared to determine which group registered the higher learning gain. Finally, the normalized learning gains of the two groups were statistically compared.

\subsection{Research instrument}

A 10-item test was used as a pre-test and post-test instrument. The test was subjected to expert validation and reliability tests. Five experts composed of three graduate school professors and two master teachers validated the test. The validity of the test obtained an outstanding rating (mean=5.0). The reliability of the test was based on stability reliability using the test-retest method (Baumgartner \& Jackson, 1999), where the correlation between the two sets of scores yields a stability reliability coefficient. The test was administered twice within 6 hours to a Grade 5 class composed of 35 students. Correlation of the test and re-test scores yielded a stability reliability coefficient of 0.945 , suggesting that the test has excellent reliability.

\section{Findings and Discussion}

\section{Table 1}

Distribution of participants by school

\begin{tabular}{|c|c|c|c|}
\hline Group/School & & Frequency & Percent \\
\hline Control Group: School A & & 45 & 33.1 \\
\hline Experimental Group A; School B & & 46 & 33.8 \\
\hline Experimental Group B: School C & & 45 & 33.1 \\
\hline & Total & 136 & 100.0 \\
\hline
\end{tabular}

Table 1 above shows the distribution of the participants or subjects of the study. The total number of participants is 136, of which 45 or $33.1 \%$ came from the Control Group from School A. Experimental Group A from school B with 46 or $33.8 \%$. And 45 or $33.1 \%$ were from Experimental Group B from School C. Thus, the participants were almost distributed equally to the three selected schools.

Table 2

Distribution of pre-test scores of participants

\begin{tabular}{|c|c|c|c|c|c|c|c|c|c|c|c|c|c|c|c|c|}
\hline \multirow{3}{*}{$\begin{array}{l}\text { School/ } \\
\text { Group }\end{array}$} & \multicolumn{14}{|c|}{ Pre-test Raw Scores } & \multirow{2}{*}{\multicolumn{2}{|c|}{$\begin{array}{c}\text { Total w/in } \\
\text { School }\end{array}$}} \\
\hline & \multicolumn{2}{|c|}{0} & \multicolumn{2}{|c|}{1} & \multicolumn{2}{|r|}{2} & \multicolumn{2}{|c|}{3} & \multicolumn{2}{|c|}{4} & \multicolumn{2}{|r|}{5} & \multicolumn{2}{|c|}{6} & & \\
\hline & $\mathrm{F}$ & $\%$ & $\mathrm{~F}$ & $\%$ & $\mathrm{~F}$ & $\%$ & $\mathrm{~F}$ & $\%$ & $\mathrm{~F}$ & $\%$ & $\mathrm{~F}$ & $\%$ & $\mathrm{~F}$ & $\%$ & $\mathrm{~F}$ & $\%$ \\
\hline School & 5 & 11.1 & 11 & 24.4 & 17 & 37.8 & 5 & 11.1 & 4 & 8.9 & 2 & 4.4 & 1 & 2.2 & 45 & 100 \\
\hline A & & 27.8 & & 30.6 & & 39.5 & & 21.7 & & 36.4 & & 50 & & 100 & & \\
\hline School & 5 & 10.9 & 13 & 28.3 & 18 & 39.1 & 9 & 19.6 & 1 & 2.2 & 0 & 0.0 & 0 & 0.0 & 46 & 100 \\
\hline B & & 27.8 & & 36.1 & & 41.9 & & 39.1 & & 9.1 & & 0.0 & & 0 & & \\
\hline School & 8 & 17.8 & 12 & 26.7 & 8 & 17.8 & 9 & 20.0 & 6 & 13.3 & 2 & 4.4 & 0 & 0.0 & 45 & 100 \\
\hline $\mathrm{C}$ & & 44.4 & & 33.3 & & 18.6 & & 39.1 & & 54.5 & & 50 & & 0 & & \\
\hline $\begin{array}{c}\text { Total } \\
\text { within }\end{array}$ & 18 & $\begin{array}{l}13.2 \\
100\end{array}$ & 36 & $\begin{array}{r}26.5 \\
100\end{array}$ & 43 & $\begin{array}{l}31.6 \\
100\end{array}$ & 23 & $\begin{array}{r}16.9 \\
100\end{array}$ & 11 & $\begin{array}{l}8.1 \\
100\end{array}$ & 4 & $\begin{array}{l}2.9 \\
100\end{array}$ & 1 & $\begin{array}{l}0.7 \\
100\end{array}$ & 136 & 100 \\
\hline
\end{tabular}

Scores the raw score within the pre-test scores.

The table reveals that the highest score obtained in the pre-test among the three schools is 6 points while the lowest score is 0 points. Only one student from School A obtained the highest score of 6 points. In terms of performance by School, 5 or $11.1 \%$ from School A obtained 0 points, 11 or $24.4 \%$ obtained 1 point, 17 or $37.8 \%$ obtained 2 points, 5 or $11.1 \%$ obtained 3 points, 4 or $8.9 \%$ obtained 4 points, 2 or $4.4 \%$ obtained 5 points, and 1 or $2.2 \%$ obtained 6 points. The majority of the students (73.3\%) from School A obtained 0-2 points. As for School B, 5 or $10.9 \%$ got 0 point, 13 or $28.3 \%$ got 1 point, 18 or $39.1 \%$ got 2 points, 9 or $19.6 \%$ got 3 points, 1 or $2.2 \%$ got 4 points, 0 or $0 \%$ got 5 points, and 0 or $0 \%$ got 6 points. Thus, the majority of the students $(78.3 \%)$ 
obtained a score from 0-2. Finally, for School C, 8 or $17.8 \%$ scored 0 point, 12 or $26.7 \%$ scored 1 point, 8 or $17.8 \%$ scored 2 points, 9 or $20 \%$ scored 3 points, 6 or $13.3 \%$ scored 4 points, 2 or $4.4 \%$ scored 5 points, and none scored 6 points. Thus, a majority of $62.3 \%$ scored from $0-2$. No students from any school obtained scores from 7 to 10. Based on the preceding data, the performance of the student participants from the three schools is more or less similar or equivalent.

In terms of the pre-test scores, of the 18 who got 0 points, 5 or $27.8 \%$ are from School A, 5 or $27.8 \%$ from School B, and 8 or $44.4 \%$ from School C. Thus, almost half of students who got 0 points are from School C. Of the 36 students who got 1 point, 11 or $30.6 \%$ are from School A, 13 or $36.1 \%$ from School B, and 12 or $33.3 \%$ from School C. Of the 43 students who got 2 points, 17 or $39.5 \%$ are from School A, 18 or $41.9 \%$ from School B, and 8 or $18.6 \%$ from School C. Of the 23 students who got 3 points, 5 or $21.7 \%$ are from School A, 9 or $39.1 \%$ from School B, and 9 or 39.1\% from School C. 11 students got 4 points distributed as follows: 4 or $36.4 \%$ from School A, 1 or $9.1 \%$ from School B, and 6 or 54.5\% from School C. As for those who obtained 5 points, 2 or $50 \%$ are from School A, none from School B and 2 or $50 \%$ from School C. Finally, the lone student who obtained 6 points, which is the highest pre-test score, is from School A only. No students scored better than 6 points from any of the three selected schools. Overall, the performance of the student participants from the three schools is more or less similar.

To further validate the observation from the descriptive statistics that the performance in the pre-test of the student participants from the three schools is similar, a one-way analysis of variance test was performed, as discussed below.

\section{Table 3}

Means and standard deviations of participants' pre-test scores

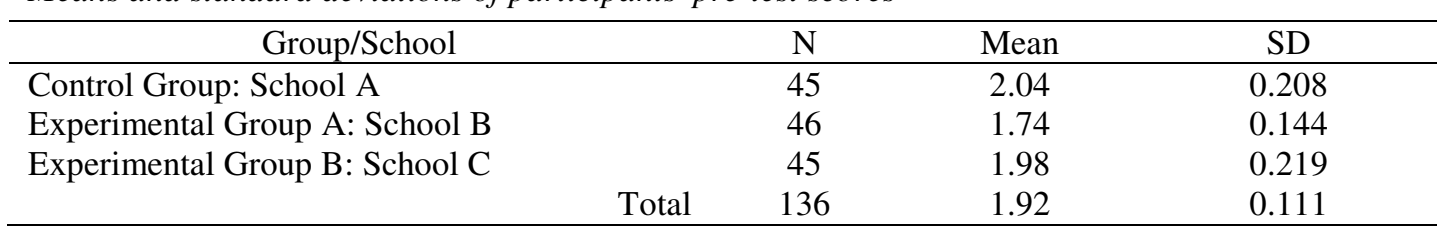

The table reveals that School A students have a mean score of $2.04 \pm 0.208$, followed by School C with $1.98 \pm 0.219$, and School B with 1.74 \pm 0.144 . Thus, it appears that School A has the highest mean score, followed by School C and School B in decreasing order. ANOVA was used to test whether the differences in the preceding means are statistically significant; the one-way analysis of variance was performed.

Table 4

ANOVA of the participants' pre-test scores

\begin{tabular}{lccccc}
\hline \multicolumn{1}{c}{ Pre-test Scores } & Sum of Squares & df & Mean Square & F & $p$-value \\
\hline Between Groups & 2.352 & 2 & 1.176 & .699 & .499 \\
Within Groups & 223.758 & 133 & 1.682 & & \\
Total & 226.110 & 135 & & & \\
\hline
\end{tabular}

Based on the table above, with an $\mathrm{F}(2,133)$ value of 0.699 and a $p$-value of 0.499 , which is higher than the alpha value of 0.05 , the differences in the means of the pre-test scores of the participants from the three schools, shown in Table 3 above, are not statistically significant. Thus, the pre-test scores of the participants from the three schools or groups are statistically similar or comparable.

The table below presents the post-test score distribution of the respondents. 
Effectiveness of PowerPaper presentation as an innovative instructional material in teaching science

Table 5

Distribution of participants' post-test scores

\begin{tabular}{|c|c|c|c|c|c|c|c|c|c|c|c|c|c|c|c|c|c|c|}
\hline \multirow{3}{*}{$\begin{array}{l}\text { School/ } \\
\text { Group }\end{array}$} & \multicolumn{16}{|c|}{ Posttest Raw Scores } & \multicolumn{2}{|c|}{ Total } \\
\hline & \multicolumn{2}{|c|}{2} & \multicolumn{2}{|r|}{3} & \multicolumn{2}{|c|}{4} & \multicolumn{2}{|c|}{5} & \multicolumn{2}{|c|}{6} & \multicolumn{2}{|c|}{7} & \multicolumn{2}{|c|}{8} & \multicolumn{2}{|c|}{9} & & \\
\hline & $\mathrm{F}$ & $\%$ & $\mathrm{~F}$ & $\%$ & $\mathrm{~F}$ & $\%$ & $\mathrm{~F}$ & $\%$ & $\mathrm{~F}$ & $\%$ & $\mathrm{~F}$ & $\%$ & $\mathrm{~F}$ & $\%$ & $\mathrm{~F}$ & $\%$ & $\mathrm{~F}$ & $\%$ \\
\hline School & 1 & 2.2 & 6 & 13.3 & 7 & 15.6 & 12 & 26.7 & 9 & 20.0 & 2 & 4.4 & 8 & 17.8 & 0 & 0 & 45 & 100 \\
\hline A & & 100 & & 85.7 & & 70.0 & & 48.0 & & 60.0 & & 6.7 & & 21.1 & & 0 & & \\
\hline School & 0 & 0.0 & 0 & 0.0 & 1 & 2.2 & 4 & 8.7 & 5 & 10.9 & 19 & 41.3 & 9 & 19.6 & 8 & 17.4 & 46 & 100 \\
\hline B & & 0.0 & & 0.0 & & 10.0 & & 16.0 & & 33.3 & & 63.3 & & 23.1 & & 80.0 & & \\
\hline School & 0 & 0.0 & 1 & 2.2 & 2 & 4.4 & 9 & 20.0 & 1 & 2.2 & 9 & 20.0 & 21 & 46.7 & 2 & 4.4 & 45 & 100 \\
\hline $\mathrm{C}$ & & 0.0 & & 14.3 & & 20.0 & & 36.0 & & 6.7 & & 30.0 & & 55.3 & & 20.0 & & \\
\hline Total & 1 & $\begin{array}{l}0.7 \\
100\end{array}$ & 7 & $\begin{array}{l}5.1 \\
100\end{array}$ & 10 & $\begin{array}{l}7.4 \\
100\end{array}$ & 25 & $\begin{array}{c}18.4 \\
100\end{array}$ & 15 & $\begin{array}{l}11.0 \\
100\end{array}$ & 30 & $\begin{array}{r}22.1 \\
100\end{array}$ & 38 & $\begin{array}{r}27.9 \\
100\end{array}$ & 10 & $\begin{array}{l}7.4 \\
100\end{array}$ & 136 & $\begin{array}{l}100 \\
100\end{array}$ \\
\hline
\end{tabular}

Note: The upper percentage refers to the percentage of the score within the School. The lower percentage in italics refers to the percentage of the raw score within the post-test scores.

The table above shows the distribution of participants' post-test scores regarding their school and raw score groupings. The table reveals that the highest score obtained is nine while the lowest score is 2 . None got a zero or perfect score.

By school performance, of the 45 School A students, 1 or $2.2 \%$ got 2 points, 6 or $13.3 \%$ got 3 points, 7 or $15.6 \%$ got 4 points, 12 or $26.7 \%$ got 5 points, 9 or $20.0 \%$ got 6 points, 2 or $2.2 \%$ got 7 points, 8 or $17.8 \%$ got 8 points, and none got 9 points. For the 46 School B students, none got 2 or 3 points, 1 or $2.2 \%$ obtained 4 points, 4 or $8.7 \%$ obtained 5 points, 5 or $10.9 \%$ obtained 6 points, 19 or $41.3 \%$ obtained 7 points, 9 or $19.6 \%$ obtained 8 points, and 8 or $17.4 \%$ obtained 9 points. Close to half of School B students obtained 7 points, and a majority score 7 points or better. For the 45 School C students, none obtained 2 points, 1 or $2.2 \%$ scored 3 points, 2 or $4.4 \%$ scored 4 points, 9 or $20.0 \%$ scored 5 points, 1 or $2.2 \%$ scored 6 points, 9 or $20.0 \%$ scored 7 points, 21 or $46.7 \%$ scored 8 points, and 2 or $4.4 \%$ scored 9 points. Close to half of the students from School C scored 8 points.

In terms of the raw scores, the lone student who obtained 2 points is from School A. Of the seven students who received 3 points, 6 or $85.7 \%$ are from School A, 1 or $14.3 \%$ from School C and none from School B. Of the ten students who obtained 4 points, 7 or $70.0 \%$ are from School A, 2 or $20.0 \%$ are from School C, and 1 or $10.0 \%$ are from School B. Of the 25 students who obtained 5 points, 12 or $48.0 \%$ are from School A. Nine or $36.0 \%$ from School C. And 4 or $16.0 \%$ from School B. Of the 15 students who obtained 6 points, 9 or $60.0 \%$ are from School A, 5 or $33.3 \%$ from School B, and 1 or $6.7 \%$ from School C. Of the 30 students who obtained 7 points, 19 or $63.3 \%$ are from School B, 9 or $30.0 \%$ are from School C, and 2 or $6.7 \%$ are from School A. Of the 38 students who scored 8 points, 21 or $55.3 \%$ from School C, 9 or $23.1 \%$ from School B, and 8 or $21.1 \%$ from School A. Finally, of the ten students who obtained 9 points, 8 or $80.0 \%$ are from School B, 2 or $20.0 \%$ are from School C, and none from School A. Thus, about $60 \%$ of the student respondents obtained a score of $7-9$ points.

ANOVA was used to determine whether there is a significant difference in the student's performance in terms of their groupings - School A as the control group and School B and School C as the experimental group an analysis of variance was performed presented below.

Table 6

Means and standard deviations of participants' post-test scores

\begin{tabular}{lccc}
\hline School & $\mathrm{N}$ & Mean & Standard Deviation \\
\hline Control Group: School A & 45 & 5.33 & 1.679 \\
Experimental Group: School B & 46 & 7.20 & 1.240 \\
Experimental Group: School C & 45 & 6.91 & 1.505 \\
Total & 136 & 6.49 & 1.686 \\
\hline
\end{tabular}


The table above shows that the control group (School A) has a mean score of 5.33 \pm 1.679 . For the

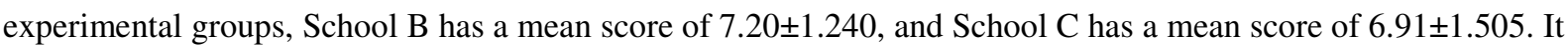
appears that the control group has the lowest mean compared to the two experimental groups. Of the two experimental groups, School B has a higher standard than School C. To determine whether there is a statistically significant difference among the three groups, the analysis of variance was performed. The table below shows the ANOVA results.

Table 7

ANOVA of the participants' post-test scores

\begin{tabular}{lccccc}
\hline \multicolumn{1}{c}{ Post-test Scores } & Sum of Squares & df & Mean Square & F & $p$-value \\
\hline Between Groups & 91.087 & 2 & 45.544 & 20.682 & 0.000 \\
Within Groups & 292.884 & 133 & 2.202 & & \\
Total & 383.971 & 135 & & & \\
\hline
\end{tabular}

Based on the table above, with an $\mathrm{F}(2,133)$ value of 20.682 and a $p$-value less than 0.001 , which is lower than the alpha value of 0.05 . Therefore, the differences in the means of the post-test scores of the participants from the three schools or groups, shown in Table 6 above, are statistically significant. Thus, the post-test scores of the participants from the three schools or groups are statistically different from each other. Because of the presence of statistically significant differences in the score of the three groups, a post hoc analysis using Scheffe's Test (George \& Mallery, 2005) was conducted with the results shown in Table 8 below.

Table 8

Multiple comparisons of participants' post-test scores

\begin{tabular}{|c|c|c|c|c|c|}
\hline (I) Group/School & (J) School & Mean Difference (I-J) & Std. Error & Sig. & Evaluation \\
\hline \multirow[t]{2}{*}{ Control Group: School A } & School B & $-1.862^{*}$ & .311 & .000 & $\mathrm{~S}$ \\
\hline & School C & $-1.578^{*}$ & .313 & .000 & S \\
\hline \multirow[t]{2}{*}{ Experimental Group A: School B } & School A & $1.862^{*}$ & .311 & .000 & $\mathrm{~S}$ \\
\hline & School C & .285 & .311 & .659 & NS \\
\hline \multirow[t]{2}{*}{ Experimental Group B: School C } & School A & $1.578^{*}$ & .313 & .000 & $\mathrm{~S}$ \\
\hline & School B & -.285 & .311 & 659 & NS \\
\hline
\end{tabular}

The table above shows the results of the post hoc analysis using Scheffe's test. As the table reveals, there is a significant difference between the control group School A and the experimental group A (School B), based on a difference of \pm 1.862 , which is significant at the .05 level $\mathrm{p}$-value is less than 0.001 . The table further reveals that there is also a significant difference between the control group School A and the experimental group B (School B) based on a mean difference of \pm 1.578 , which is significant at the .05 level since the $p$-value for it is less than 0.001. Thus, between the two experimental groups, A (School B) and B (School C) is not significant based on a mean difference of \pm 0.285 with a $p$-value of 0.659 , which is greater than the alpha value of 0.05 .

Based on these results, the respective post-test performance of the two experimental groups is compared statistically with each other but significantly higher than that of the control group. As stated otherwise, the performance in the post-test of the control group School A is significantly lower than the performance of the two experimental groups, School B and School C. The student participants from School B and School C who were taught using the PowerPaper Presentation performed significantly higher in the post-test than the student participants from School A. The latter was conducted in the traditional method without the use of PowerPaper Presentation. This finding is associated with the work of Adalikwu and Iorkpilgh (2013) that innovative instructional materials provide a structured and organized learning supports to the learners where the learners show their interest in what is being discussed and therefore enhancing the learning process of learners with diverse learning needs.

Therefore, the results imply that using the PowerPaper Presentation effectively promotes students' learning of the selected concepts. 
Effectiveness of PowerPaper presentation as an innovative instructional material in teaching science

Table 9

t-test results for the participants' pre-test and post-test scores

\begin{tabular}{|c|c|c|c|c|c|c|c|c|c|}
\hline Group/School & $\mathrm{N}$ & $\begin{array}{l}\text { Pre-test } \\
\text { Mean }\end{array}$ & SD & $\begin{array}{l}\text { Post-test } \\
\text { Mean }\end{array}$ & SD & t-test & df & $p$-value & Remarks \\
\hline $\begin{array}{l}\text { Control Group: } \\
\text { School A }\end{array}$ & 45 & 2.04 & 1.397 & 5.33 & 1.679 & -12.774 & 44 & 0.000 & $S$ \\
\hline $\begin{array}{l}\text { Experimental } \\
\text { Group A: School } \\
\text { B }\end{array}$ & 46 & 1.74 & 0.976 & 7.20 & 1.240 & -22.718 & 45 & 0.000 & $\mathrm{~S}$ \\
\hline $\begin{array}{l}\text { Experimental } \\
\text { Group B: } \\
\text { School C }\end{array}$ & 45 & 1.98 & 1.469 & 6.91 & 1.505 & -16.326 & 44 & 0.000 & $\mathrm{~S}$ \\
\hline
\end{tabular}

With a $\mathrm{t}=-12.774$, $\mathrm{df}=44$, and a $p$-value $<0.001$, the post-test mean score $(5.33 \pm 1.679)$ of the control group School A is statistically higher than its pre-test mean score $(2.04 \pm 1.397)$. Therefore, the control group performed significantly better in the post-test than the pre-test after teaching. With a $\mathrm{t}=-22.718$, $\mathrm{df}=45$, and $p$-value $<0.001$, the post-test mean score (7.20 \pm 1.240$)$ of the experimental group A (School B) is significantly higher than its pre-test mean score (1.74 \pm 0.976$)$. Therefore, the School B students performed significantly better in the post-test than the pre-test after teaching.

Finally, with a $\mathrm{t}=-16.326$, $\mathrm{df}=44$, and $\mathrm{p}$-value $<0.001$, the post-test mean score $(6.91 \pm 1.505)$ of the experimental group B (School B) is significantly higher than its pre-test mean score (1.98 \pm 1.469$)$. Therefore, the experimental group School C performed significantly better in the post-test than the pre-test after teaching. Based on the initial results, it appears that the teaching conducted by the researcher after the pre-test administration significantly improved the student participants' performance in all three groups, as shown by their significantly higher post-test mean scores. This finding is defended by Kaspar et al. (2017) that instructional materials encourage, promote, and improve learning and teaching processes. A comparative analysis of the learning gains of the control and experimental groups is presented below.

Table 10

Means and standard deviations of participants' learning gains

\begin{tabular}{|c|c|c|c|}
\hline Group/School & $\mathrm{N}$ & Mean & Std. Deviation \\
\hline Control Group: School A & 45 & 40.6481 & 19.79966 \\
\hline Experimental Group A: School B & 46 & 65.3433 & 17.37984 \\
\hline Experimental Group B: School C & 45 & 60.4568 & 19.35932 \\
\hline Total & 136 & 55.5553 & 21.57167 \\
\hline
\end{tabular}

The table above shows some descriptive statistics of the participants' learning gains regarding mean and standard deviations. The table reveals that the control group School A has a mean normalized learning gain of $40.65 \pm 19.80 \%$. It means that the students in the control group registered an approximate $41 \%$ increase in their learning after teaching using the traditional method only. Experimental Group A (School B) has a mean normalized learning gain of $65.34 \pm 17.38 \%$. It implies that the Experimental Group A (School B) students registered an average learning gain of $65 \%$ after the teaching intervention with PowerPaper Presentation. Finally, Experimental Group B (School C) obtained a mean normalized learning gain of $60.46 \pm 19.36 \%$. This suggests that the Experimental Group B (School C) students registered an approximate average learning gain of $60 \%$ after the teaching intervention using PowerPaper Presentation. This finding is related to the works of Igiri and Effiong (2015) that the use of instructional materials brings out more effective and meaningful learning outcomes. The one-way analysis of variance was performed to test whether there are significant differences in the student participants' learning gains. 


\section{Table 11}

ANOVA results for participants' normalized learning gains

\begin{tabular}{lccccc}
\hline \multicolumn{1}{c}{ Learning Gains } & Sum of Squares & df & Mean Square & F & Sig. \\
\hline Between Groups & 15488.214 & 2 & 7744.107 & 21.760 & 0.000 \\
Within Groups & 47332.265 & 133 & 355.882 & & \\
Total & 62820.479 & 135 & & & \\
\hline
\end{tabular}

Based on the table above, with an $\mathrm{F}(2,133)=21.760$ having a $p$-value $<0.001$, the student participants' normalized learning gains when organized by groups (control vs. experimental) or schools is statistically and significantly different. Therefore, it implies that the learning gains of the students in the three groups differ significantly. A post-hoc test, specifically the Scheffe's test, was performed to determine where the differences lie.

\section{Table 12}

Multiple comparison of participants' learning gains

\begin{tabular}{|c|c|c|c|c|c|}
\hline (I) Group/School & (J) School & Mean Difference (I-J) & Std. Error & Sig. & Evaluation \\
\hline \multirow[t]{2}{*}{ Control Group: School A } & BPES & $-24.69519^{*}$ & 3.95538 & .000 & $\mathrm{~S}$ \\
\hline & SJES & $-19.80864^{*}$ & 3.97705 & .000 & S \\
\hline \multirow[t]{2}{*}{ Experimental Group A: School B } & CCAES & $24.69519^{*}$ & 3.95538 & .000 & S \\
\hline & SJES & 4.88655 & 3.95538 & .468 & NS \\
\hline \multirow[t]{2}{*}{ Experimental Group B: School C } & CCAES & $19.80864^{*}$ & 3.97705 & .000 & $\mathrm{~S}$ \\
\hline & BPES & -4.88655 & 3.95538 & .468 & NS \\
\hline
\end{tabular}

Based on the table above, the learning gains of the control group differ significantly from experimental group A based on a mean difference of \pm 24.69519 with a $p$-value $<0.001$. This means that the learning gains of students from School B are significantly higher than the students of School A. In addition, the learning gains of the control group differ considerably from that of experimental group B based on a mean difference of \pm 19.80864 with a $p$-value $<0.001$. This implies that the student's learning gains from School $\mathrm{C}$ are significantly higher than that of the students from School A. Finally, the learning gains of the two experimental groups are not significant based on their mean difference of \pm 4.88655 with a $p$-value of 0.468 , which is greater than the alpha value of 0.05 . This implies that the learning gains of the students from the two experimental groups are statistically comparable.

Based on the initial results, the learning gains of the two experimental groups A (School B) and B (School C), while statistically comparable, are significantly higher than that of the control group. This implies that the higher learning gains of the experimental groups compared to the control group may be associated with using the PowerPaper Presentation. This finding is supported by the work of Naz and Murad (2017) that innovative instructional materials capture interest and extend the range of sense organs among students. Furthermore, it supplements a concrete basis for conceptual thinking and provides a reality experience that develops a continuity of learning thought, which enriches the learning processes. Thus, the PowerPaper Presentation can bring about significant learning gains in the selected science topics where it is used.

\section{Conclusion}

Based on the significant findings presented above, the following conclusions are as a result of this demonstrated: The pre-test scores of the pupils in the control group (School A) and the two experimental groups, A (School B) and B (School C), did not differ significantly. Thus, despite some differences, the scores of the three groups were statistically comparable. The post-test scores of the pupils in the control and experimental groups after teaching the lesson using PowerPaper Presentation varied significantly. The post-test scores of the experimental groups A (School B) and B (School C) were statistically comparable but significantly higher than the control group (School A). Therefore, the null hypothesis is not accepted. 
The learning gains of the control group (School A) registered an approximate average of $41 \%$, experimental group A (School B) an average of 65\%, while experimental group B (School C) an average of 60\%. There is a significant difference between the learning gains of the control and experimental groups. For example, the experimental groups' A (School B) and B (School C) showed statistically comparable learning gains. But the learning gains of the two experimental groups were statically higher than that of the control group (School A). Therefore, the null hypothesis is not accepted. The PowerPaper Presentation as an educational innovation is an effective, low-cost, and low-tech alternative to promote students' learning of selected topics in Science 5 that teachers assigned to schools with inadequate ICT resources can utilize to improve their teaching.

\section{References}

Akhlaghi, M., \& Zareian, G. (2015). The effect of powerpoint presentation on grammar and vocabulary learning of Iranian pre-university EFL learners. Academic Research International, 6(1), 160.

Alkash, K. A. M., \& Al-Dersi, Z. E. M. (2017). Advantages of using PowerPoint presentation in EFL classroom $\&$ the status of its use in Sebha University. Tersedia. http://eltsjournal.org/upload/2014-05-13

Galloway, R., \& Lancaster, S. (2016). Learning gains. Retrieved from https://eic.rsc.org/feature/learning-gains/2000094.article

Gambari, A. I., Yusuf, H. T., \& Balogun, S. A. (2015). Effectiveness of powerpoint presentation on students' cognitive achievement in technical drawing. Malaysian Online Journal of Educational Technology, 3(4), $1-12$.

Igiri, C. E., \& Effiong, O. E. (2015). Impact of instructional materials in teaching and learning biology in senior secondary schools in Yakurr LG A. International Letters of Social and Humanistic Sciences, 62, 27-33. https://doi.org/10.18052/www.scipress.com/ILSHS.62.27

Inoue-Smith, Y. (2016). College-based case studies in using PowerPoint effectively. Cogent Education, 3(1), 1127745. https://doi.org/10.1080/2331186X.2015.1127745

Kaspar, W., Borgerding, J., Hodge, M., \& Marino, B. (2017). PRIMO: Peer-reviewed instructional materials online. College and Research Libraries, 78, 2-7. https://doi.org/10.5860/crl.78.1.2

Khobragade, S., Abas, A. L., \& Khobragade, Y. S. (2016). Comparative study on the measurement of learning outcomes after PowerPoint presentation and problem-based learning discussed family medicine amongst fifth-year medical students. Journal of family medicine and primary care, 5(2), 298. https://doi.org/10.4103/2249-4863.192350

Lewis, B. (2018). TLM or teaching-learning materials definition. Available at https://web.archive.org/web/20180414170042/https://www.thoughtco.com/tlm-teaching-learning-materi $\underline{\text { als-2081658 }}$

McGuire, S. (2018). 10 Types of Visual Aids for Learning [+ Teaching Aid Templates]. Retrieved August 23, 2019, from https://venngage.com/blog/visual-aids-for-learning-templates/

Naz, F., \& Murad, H. S. (2017). Innovative teaching has a positive impact on the performance of diverse students. SAGE Open, 7(4). https://doi.org/10.1177/2158244017734022

Petimani, M. S., \& Adake, P. (2015). Blackboard versus PowerPoint presentation: Students opinion in medical education. International Journal of Educational and Psychological Researches, 1(4), 289. https://doi.org/10.4103/2395-2296.163935

Rowsell, J., Morrell, E., \& Alvermann, D. E. (2017). Confronting the digital divide: Debunking brave new world discourses. The Reading Teacher, 71(2), 157-165. https://doi.org/10.1002/trtr.1603

Star, L. (2011). PowerPoint I Creating Classroom Presentations. Retrieved August 23, 2019, from http://www.educationworld.com/a tech/tech/tech013.shtml

Worthington, D. L., \& Levasseur, D. G. (2015). To provide or not to provide course PowerPoint slides? The impact of instructor-provided slides upon student attendance and performance. Computers \& Education, 85, 14-22. https://doi.org/10.1016/j.compedu.2015.02.002 
Anacaya, R. Z.

120 Consortia Academia Publishing (A partner of Network of Professional Researchers and Educators) 
